\title{
Measurement of soil suction using moist filter paper
}

\author{
Eng-Choon Leong ${ }^{\mathrm{a}}$, Richard Kizza and Harianto Rahardjo \\ Nanyang Technological University, School of Civil and Environmental Engineering, Blk N1, 50 Nanyang Avenue, Singapore 639798
}

\begin{abstract}
Measurement of soil suction is important as soil suction is one of the two stress-state variables that control both the hydro and mechanical behaviour of unsaturated soils. One of the soil suction measurement techniques is the filter paper method. Even though the filter paper technique has been standardized, the experimental procedure can still be improved in order to reduce the inconsistencies that are often reported with the filter paper technique. This paper explores usage of both initially dry and initially moist Whatman No. 42 filter paper for matric and total suction measurements. Residual soils from the Bukit Timah Granite in Singapore were compacted at various water contents from dry to wet of optimum using standard Proctor energies and their suctions were measured using both contact and non-contact filter papers. Results of the suction measurements showed hysteresis between the initially dry and the initially moist filter papers for both the contact and non-contact methods. Suction measurement by the contact filter paper method is more consistent than suction measurement by the non-contact filter paper method. Condensation causes the non-contact filter papers to have higher water contents. The results showed that the non-contact initially dry filter paper follows the total suction curve but the non-contact initially moist filter paper may follow the matric suction curve instead.
\end{abstract}

\section{Introduction}

In order to understand fully the behavior of unsaturated soils, measurement of soil suction is essential. Suction influences both the hydro and mechanical behavior of unsaturated soils. Despite its importance, measurement is difficult largely due to the reliability of the existing techniques. One such measurement technique uses the filter paper. The filter paper is economical, easily accessible, easy to use, relatively accurate if a strict protocol is followed and measures a wide range of soil suction. However, despite being standardized in ASTM D5298-10 [1], the experimental procedures are still controversial and research is being performed to better understand the technique. Substantial contributions to the filter paper suction measurement technique have been made by Al-Khafaf and Hanks [2], Houston et al. [3], Bulut et al. [4], Likos and Lu [5], Leong et al. [6], Marinho and Oliveira [7], Bicalho et al. [8], Bulut and Leong [9], Haghighi et al. [10] and Marinho and da Silva Gomes [11].

Houston et al. [3], Bulut et al. [4] and Leong et al. [6] suggested different calibration curves for total and matric suction measurements but Marinho and Oliveira [7] suggested that the calibration curve is unique for both total and matric suction measurements. The different calibration curves for the Whatman No. 42 filter curve suggested by Leong et al. [6] are shown in Figure 1. Marinho and Olivera [7] attributed the differences to equilibrium times as shown in Figure 2. Based on their findings, Marinho and Olivera [7] recommended different equilibrium times for the non-contact filter paper based on the total suction range reproduced in Table 1 . The recommended equilibrium time for the filter paper method in ASTM D5298-10 [1] is 15 days and this was an increase from the previously recommended equilibrium time of 7 days.

Some investigators have pointed out the existence of hysteresis between the drying and wetting filter papers $[6$, $12,13]$. However, very little experimental data exist to show the effects of hysteresis of the filter paper on the suction measurement. According to Leong et al. [6], the hysteresis between a wet and dry filter paper ranges between 1 and $5 \%$ of the filter paper water contents. This amount of hysteresis is small but may be considerable when used to measure suction in the low range.

\footnotetext{
$\bar{a}$ Corresponding author: cecleong@ntu.edu.sg
} 


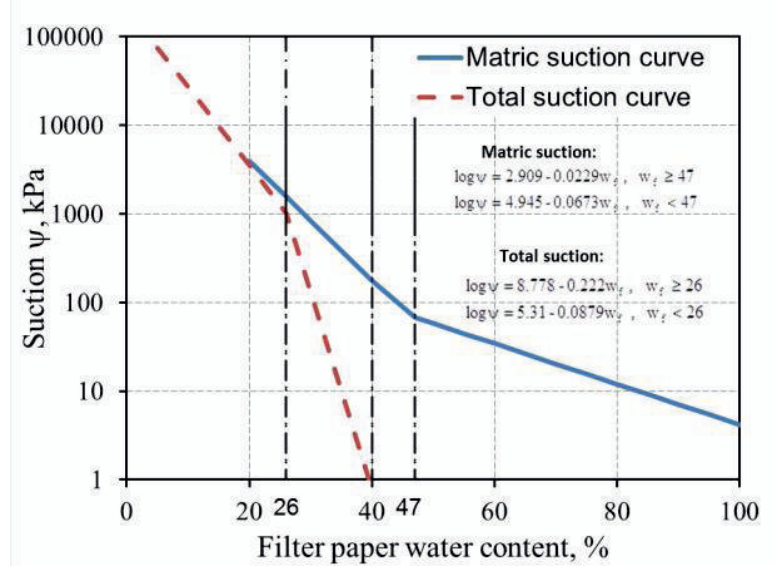

Figure 1. Matric and total suction curves for Whatman No. 42 filter paper.

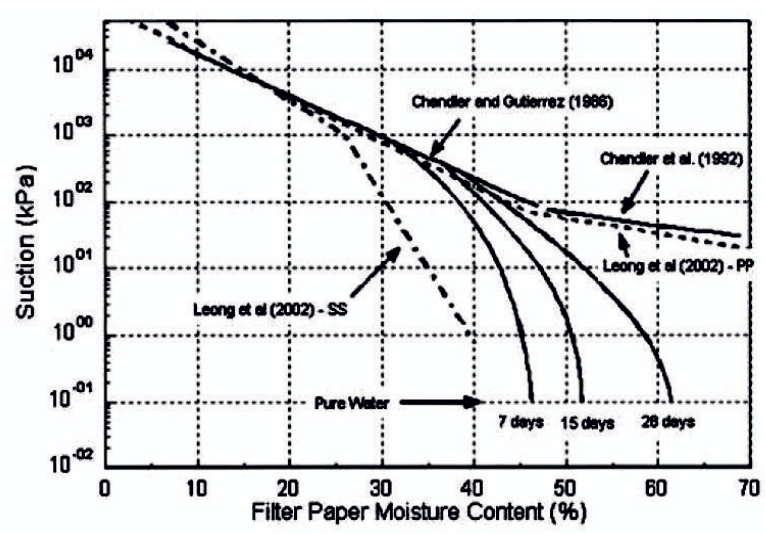

Figure 2. Effect of equilibrium time and distance from the water source (from [7]).

To address the above, this paper investigates the use of initially dry and initially moist Whatman No. 42 filter paper for suction measurement in the range from 0 to $1000 \mathrm{kPa}$ corresponding to filter paper water content of more than $20 \%$ using dynamically compacted soils as the suction source. The use of initially moist filter papers will reduce the equilibrium time if it is indeed affecting the differences in calibration equations for the Whatman No. 42 filter paper.

Table 1. Suggested equilibrium time for total suction measurement as function of the suction level for Whatman No. 42 filter paper (from [7]).

\begin{tabular}{|c|c|}
\hline $\begin{array}{c}\text { Total Suction Range } \\
(\mathbf{k P a})\end{array}$ & Equilibrium Time Suggested \\
\hline $0-100$ & $\begin{array}{c}\text { Not determined, but certainly more } \\
\text { than } 30 \text { days }\end{array}$ \\
\hline $100-250$ & 30 days \\
\hline $250-1000$ & 15 days \\
\hline $1000-30000$ & 7 days \\
\hline
\end{tabular}

\section{Materials and methods}

\subsection{Residual soils}

Suction measurements were performed on compacted residual soil samples. The residual soils are from the Bukit Timah Granite of Singapore [14]. The residual soil was air dried and sieved through No. 4 sieve $(4.75 \mathrm{~mm})$. Only the soils passing through the No. 4 sieve were used in the study. The basic soil properties are liquid limit, $\mathrm{w}_{\mathrm{L}}$ $=58$, plastic limit, $\mathrm{W}_{\mathrm{P}}=31$, specific gravity, $\mathrm{G}_{\mathrm{s}}=2.7$. The grain size distribution revealed that the soil consists of $27 \%$ sand and $73 \%$ fines. According to the Unified Soil Classification System, the soil is classified as $\mathrm{MH}$ (inorganic silt). The standard Proctor compaction curve of the residual soil is determined in accordance with ASTM D698-12 [15] and shown in Figure 3. For the compaction, distilled water was used. The maximum dry unit weight is $1.68 \mathrm{Mg} / \mathrm{m} 3$ and the optimum water content is $16 \%$.

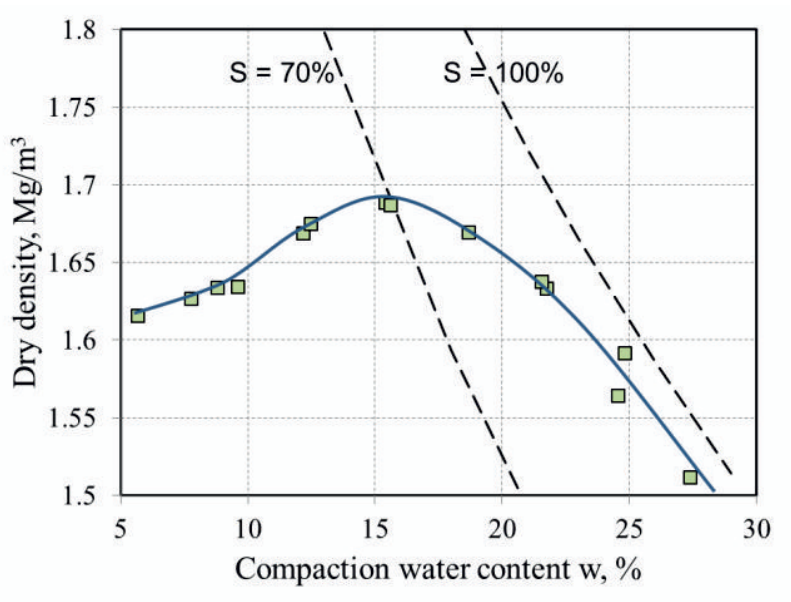

Figure 3. Standard Proctor compaction curve.

\subsection{Filter paper methods}

In this study, both the contact and non-contact filter papers were used to measure the matric and total suctions, respectively. Both initially dry and initially moist filter papers were used. The initially dry filter papers were used as obtained directly from their boxes while the initially moist filter papers were initially soaked in distilled water for about 15 minutes and then left to dry to a moist state for two hours in a room whose relative humidity was between 60 and $70 \%$ and room temperature was between 24 and $26^{\circ} \mathrm{C}$. In all cases, the filter papers were handled using a clean pair of tweezers with gloved hands to ensure no contamination of filter papers.

A number of compacted soil samples were made at various water contents from dry to wet of optimum to provide a range of suctions for measurements. Approximately cylindrical soil specimens were carefully trimmed from the compacted samples such that they occupy at least $75 \%$ of the volume of the air-tight containers with internal diameter of $85 \mathrm{~mm}$ and height of $70 \mathrm{~mm}$. Next, the cylindrical specimens were sliced at the middle into two approximately equal pieces. The contact filter paper was sandwiched between the two soil slices and the joint was sealed off using electrical tape to ensure no moisture loss. The soil slices were then further wrapped in three layers of cling wrap on its sides and at its bottom before placing them into the air-tight 
container. A PVC ring (diameter $40 \mathrm{~mm}$ and thickness $5 \mathrm{~mm}$ ) was placed on top of the soil specimen onto which the non-contact filter paper was placed. The test specimen was then sealed in the air-tight container. All the containers containing the test specimens were transferred into a styrofoam box and stored for up to 21 days. At the end of 21 days, the contact and no-contact filter papers were retrieved and their water contents were determined following the procedures suggested by Bulut et al. [4]. An equilibrium period of 21 days was chosen as it exceeds the equilibrium period of 15 days recommended ASTM D5298-10 [1]. In addition, the maximum suction of the compacted soil samples was expected to be less than $1000 \mathrm{kPa}$ and hence 21 days also exceeded the equilibrium period of 15 days recommended by Marinho and Oliveira [7].

\section{Results and discussion}

\subsection{Contact filter paper}

Figure 4 shows the results of the contact filter papers. Figure 4(a) shows both initially dry and initially moist filter paper water contents plotted against compaction water contents. Figure 4(b) shows the matric suction obtained using the equation for the matric suction calibration curve shown in Figure 1. The initially dry and initially moist filter papers display a distinct hysteresis in their water contents. A difference of about $5 \%$ water content is observed between the initially dry and initially moist filter papers for all the soils tested, in agreement with the observations of Leong et al. [6]. It is expected that the compacted soil specimens at the same water content will have the same matric suction. Thus, the matric suction calibration curve for the contact filter paper method should be different for the initially dry and the initially moist filter papers. The filter paper water content increases with increase in the compaction water content. Increase in compaction water content represents a decrease in matric suction $[16,17]$.

\subsection{Non-contact filter paper}

Figure 5 shows the results of the non-contact filter papers. Figure 5(a) shows both initially dry and initially moist filter paper water contents plotted against compaction water contents. Figure 5(a) shows that the hysteresis is less distinct when compared with that for the contact filter paper method but it is still present with the initially moist filter papers registering higher water contents compared to the initially dry filter papers. In addition, Figure 5(a) shows that the filter papers with water contents above $40 \%$ showed wider scatter for both initially dry and initially moist filter paper. Comparing Figures 4(a) and 5(a) suggests that the water contents are similar with compaction water content and thus the matric suction curve in Figure 1 should also be used to infer the total suction from the non-contact filter papers. Figure 5(b) shows the total suction obtained using the

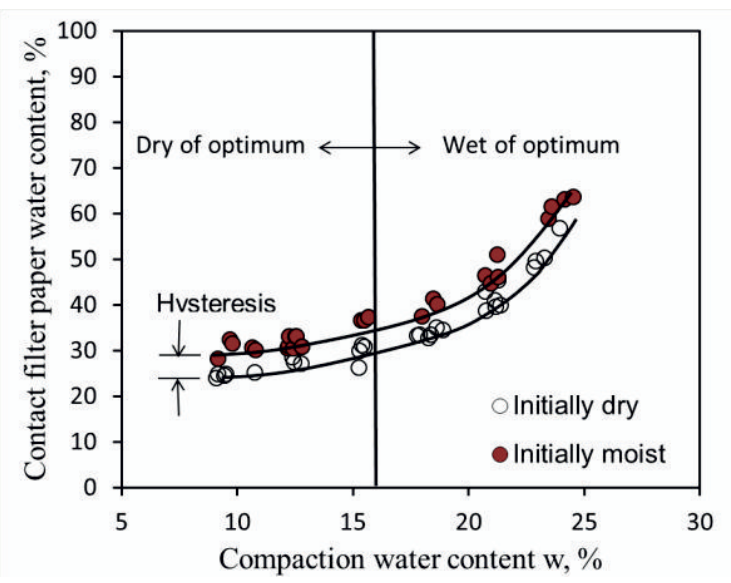

(a) Contact filter paper water content versus compaction water content.

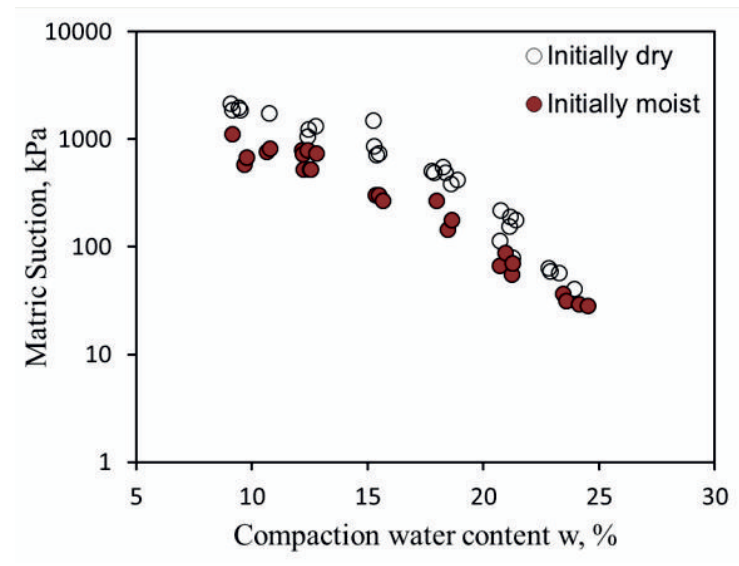

(b) Matric suction versus compaction water content

Figure 4. Measurement of suction using contact filter papers.

equation for the matric suction curve shown in Figure 1. From Figure 1, it is expected that a non-contact initially dry filter paper follows the total suction curve and will not attain water contents higher than $40 \%$ The above seems to support the suggestion by Marinho and Oliveira [7] that the filter paper calibration curve should be unique and there should not be a total suction curve for filter paper. However, it will be shown later why Figure $5 b$ is misleading.

\subsection{Initially dry and initially moist filter papers compared}

The contact and non-contact initially dry filter paper results are compared in Figure 6. The contact and noncontact filter paper water contents of the initially dry filter paper seem to agree with each other following a similar trend with the compaction water content. However, above $40 \%$ filter paper water content the noncontact filter paper shows a greater scatter. This observation seems logical as the compacted residual soil specimens were compacted with distilled water and if salt 
was absent from the soil, osmotic suction is absent and matric suction should be the same as total suction. Hence, the water contents of the contact and non-contact filter paper water contents should be similar.

The contact and non-contact initially moist filter papers are compared in Figure 7. Similar to Figure 6, the contact and non-contact filter paper water contents of the initially moist filter paper seem to agree with each other following a similar trend with the compaction water content. However, a greater scatter in the non-contact initially moist filter paper is observed especially when the filter paper water content is greater than $40 \%$.

Based on Figures 6 and 7, it appears that the calibration equation for the filter paper should be unique and independent of the filter paper method, that is, contact or non-contact. To validate this observation, the filter paper calibration curves shown in Figure 1 need to be recovered from the non-contact filter paper measurements.

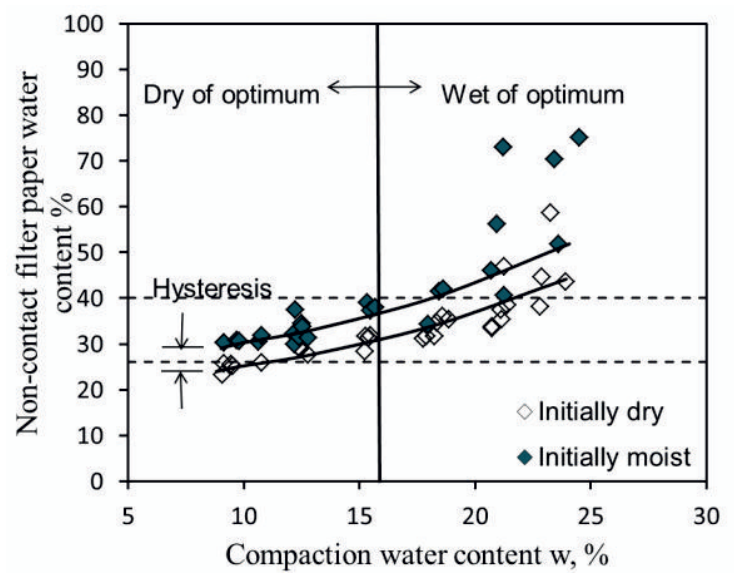

(a) Non-contact filter paper water content versus compaction water content.

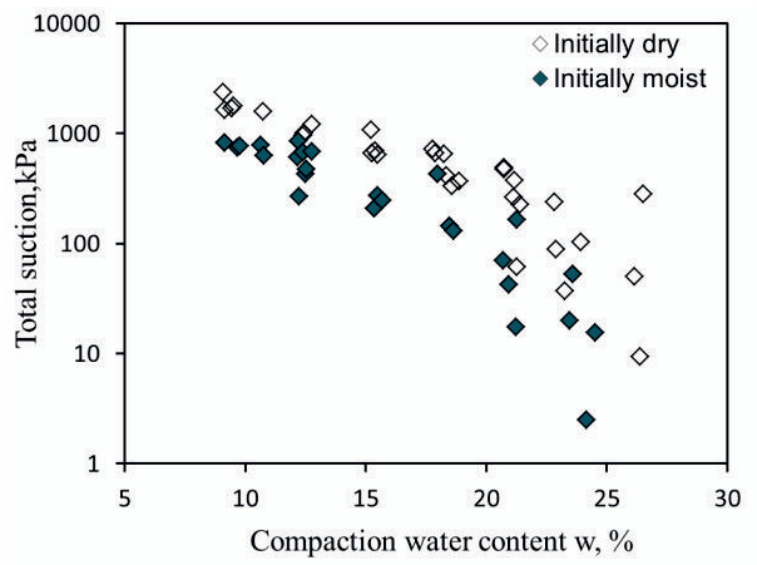

(b) Total suction versus compaction water content

Figure 5. Measurement of suction using non-contact filter papers.

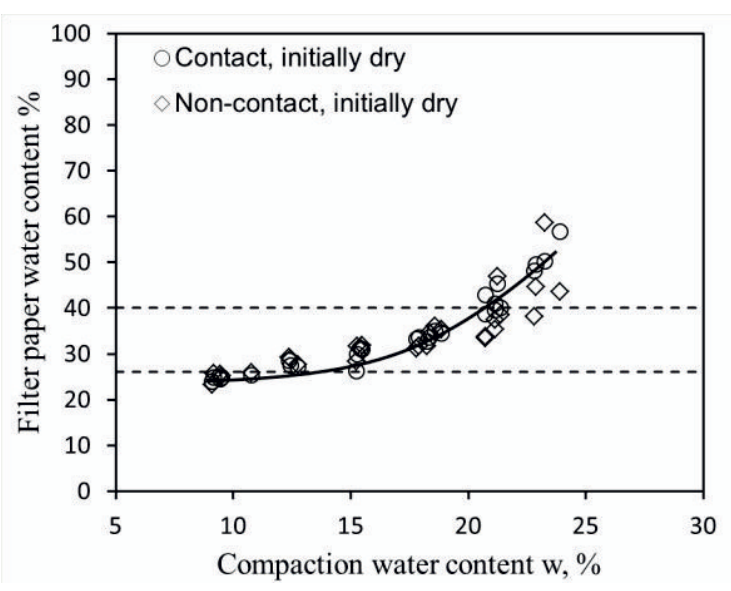

Figure 6. Contact and non-contact initially dry filter paper water content versus compaction water content.

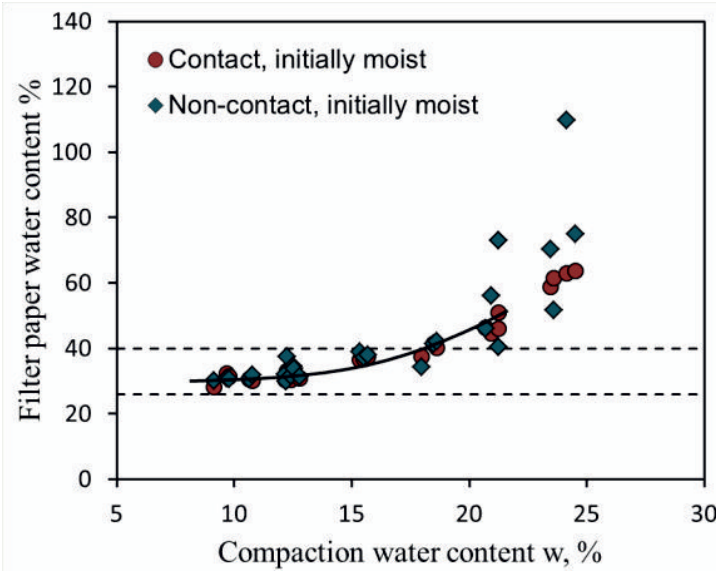

Figure 7. Contact and non-contact initially moist filter paper water contents versus compaction water content.

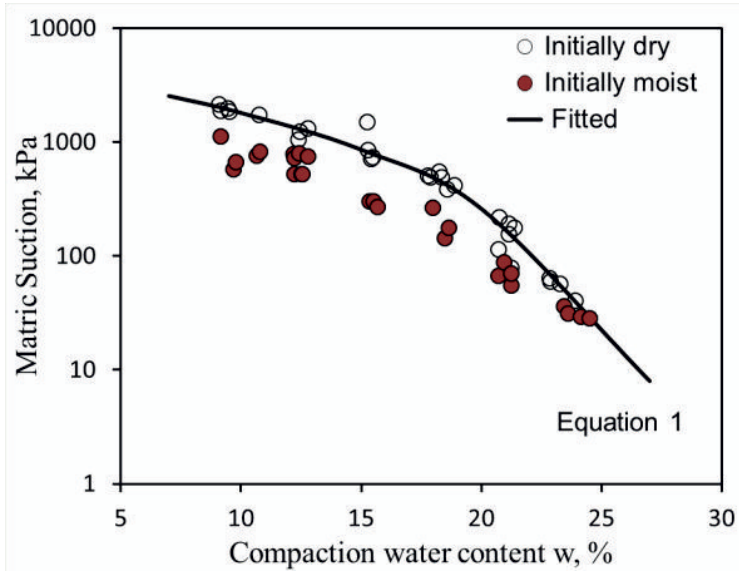

Figure 8. Relationship between soil suction and compaction water content of $7-27 \%$ of the soil. 


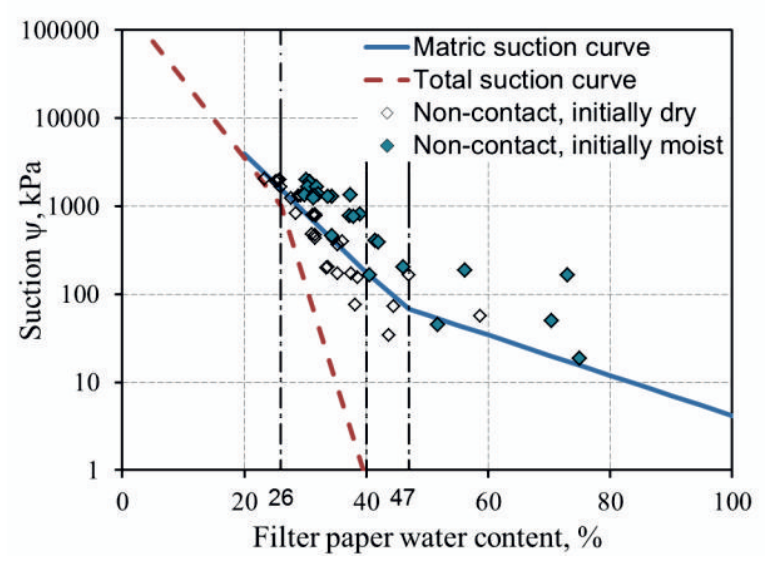

Figure 9. Suctions from non-contact initially dry and initially moist filter papers.

Figure $4 \mathrm{a}$ shows that the suction of the compacted soil can be reliably measured using the contact filter paper method. As the filter paper calibration curves were obtained from initially dry filter papers, the suctions shown by the initially dry filter papers in Figure $4 \mathrm{~b}$ should give the matric and total suctions of the compacted soils. The relationship between suction and compaction water content of $7-27 \%$ for the soil is:

$$
\psi=7 w^{2}-365 w+4760
$$

where $\psi$ is soil suction and $\mathrm{w}$ is compaction water content in \%. Equation 1 is shown in Figure 8. Once the matric suction of the compacted soil for any compaction water content is known, it can be treated as a suction source for the non-contact filter paper method. Figure 9 shows the plot of the soil suction versus the non-contact filter paper water contents.

The non-contact initially dry filter paper water contents are expected to straddle the total suction curve but the data are mostly between the total suction and the matric suction curves. For the non-contact initially moist filter paper water contents, there could be two possible outcomes: The water content of the non-contact initially moist filter paper is expected to approach either the matric suction curve or the total suction curve. However, almost all of the non-contact initially moist filter paper water contents are above the matric suction curve.

The above observations can only be explained by the person conducting the experiments. At total suctions less than $1000 \mathrm{kPa}$, the relative humidity at $25^{\circ} \mathrm{C}$ is above $99 \%$ and condensation was frequently observed as small beads of water on the inside of the lid of the airtight container above the non-contact filter paper. Therefore, there was a high possibility of the water from the condensation falling onto the non-contact filter paper giving a higher than expected filter paper water content as observed in Figure 8. Thus, the water contents of the initially dry filter paper were higher than the total suction curve and the water contents of the initially moist filter paper were higher than that of the initially dry filter paper. While it is shown that the total suction calibration curve should be used for the non-contact initially dry filter paper, it has not been established irrefutably if a different calibration curve is applicable for the noncontact initially moist filter paper. Currently, experiments are ongoing to provide the answer.

\section{Conclusion}

All filter paper calibration curves were developed using initially dry filter papers. In this paper, both initially dry and initially moist filter papers were used to measure both matric and total suctions. The measurement results showed that there was hysteresis between the initially dry and the initially moist filter papers with the initially moist filter papers giving correspondingly higher water content for the same compacted soil sample. For the non-contact filter paper method, both the initially dry and initially moist filter papers showed a higher than expected water content due to condensation. The calibration curve that should be used for the non-contact initially dry filter paper should be the total suction curve. However, it is not clear if the calibration curve for the non-contact initially moist filter paper should be the matric suction curve. Tests are ongoing to provide the answer in the near future.

\section{Acknowledgement}

The second author acknowledges the scholarship from the Singapore International Graduate Award (SINGA) administered by the Agency for Science, Technology \& Research (A*STAR) and the Nanyang Technological University (NTU).

\section{References}

1. ASTM D5298-10, ASTM International, www.astm.org (2010).

2. S. Al-Khafaf, R. Hanks, Soil Sci., 117(4), 194-199, (1974).

3. S.L. Houston, W.N., Houston, A.M. Wagner, 1994, Geotech. Test. J., 17(2), 185-194 (1994).

4. R. Bulut, R.L. Lytton, W.K. Wray, W. K. (2001) Expansive clay soils and vegetative influence on shallow foundations, 243-261 (2001).

5. W.J. Likos, N. Lu, N. (2002) TRR: Journal of the Transport. Res. Board 1786(1), 120-128 (2002).

6. E.C. Leong, L. He, H. Rahardjo, ASTM Geotech. Testing J., 25(3), 322-333 (2002).

7. F.A.M. Marinho, O.M. Oliveira, O. M. ASTM Geotech. Testing J., 29(3), 250-258 (2006).

8. K.V. Bicalho, A.G. Correia, S.R. Ferreira, J.-M. Fleureau, F.A.M. Marinho, Proc. XIII Pan-Am. Conf. Soil Mech. Geotech Eng., 215-219 (2007).

9. R. Bulut, E.C. Leong, Geotech Geol. Eng., 26(6), 633-644 (2008).

10. A. Haghighi, G.M. Medero, F.A.M. Marinho, B. Mercier, P.K. Woodward, ASTM Geotech. Testing J., 35(1), 83-90 (2012).

11. F.A. Marinho, J.E. da Silva Gomes, J. E. ASTM Geotech. Testing J., 35(1), 172-181 (2012). 
12. G.E. Swarbrick, Proc. 1st Int. Conf. Unsaturated Soils, 2, 701-708 (1995).

13. B. Harrison, G. Blight, Proc. of the 2nd Int. Conf. Unsaturated Soils, 1, 362-367 (1995).

14. E.C. Leong, H. Rahardjo, S.K. Tang, International workshop on characterisation and engineering properties of natural soils, Singapore, 2, 1279-1304 (2002).
15. ASTM D698-12, ASTM International, www.astm.org (2012).

16. E.C. Leong, S. Tripathy, H. Rahardjo, ASTM Geotech. Testing J., 27(3), 322 - 331 (2004).

17. E.C. Leong, S. Widiastuti, C.C. Lee, H. Rahardjo, Geotechnique, 57(6), 547-556 (2007). 